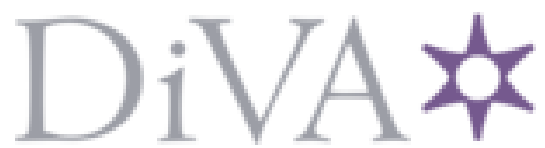

http://www.diva-portal.org

This is the published version of a chapter published in Seaweed and microalgae as alternative sources of protein.

Citation for the original published chapter:

Thomas, J-B., Potting, J., Gröndahl, F. (2021)

Environmental impacts of seaweed cultivation: kelp farming and preservation

In: Xin Gen Lei (ed.), Seaweed and microalgae as alternative sources of protein UK:

Burleigh Dodds Science Publishing Ltd

https://doi.org/10.19103/AS.2021.0091.11

N.B. When citing this work, cite the original published chapter.

Permanent link to this version:

http://urn.kb.se/resolve?urn=urn:nbn:se:kth:diva-303331 


\section{Environmental impacts of seaweed cultivation: kelp farming and preservation}

Jean-Baptiste Thomas, KTH Royal Institute of Technology, Sweden; José Potting, EnviroSpotting, The Netherlands and KTH Royal Institute of Technology, Sweden; and Fredrik Gröndahl, KTH Royal Institute of Technology, Sweden

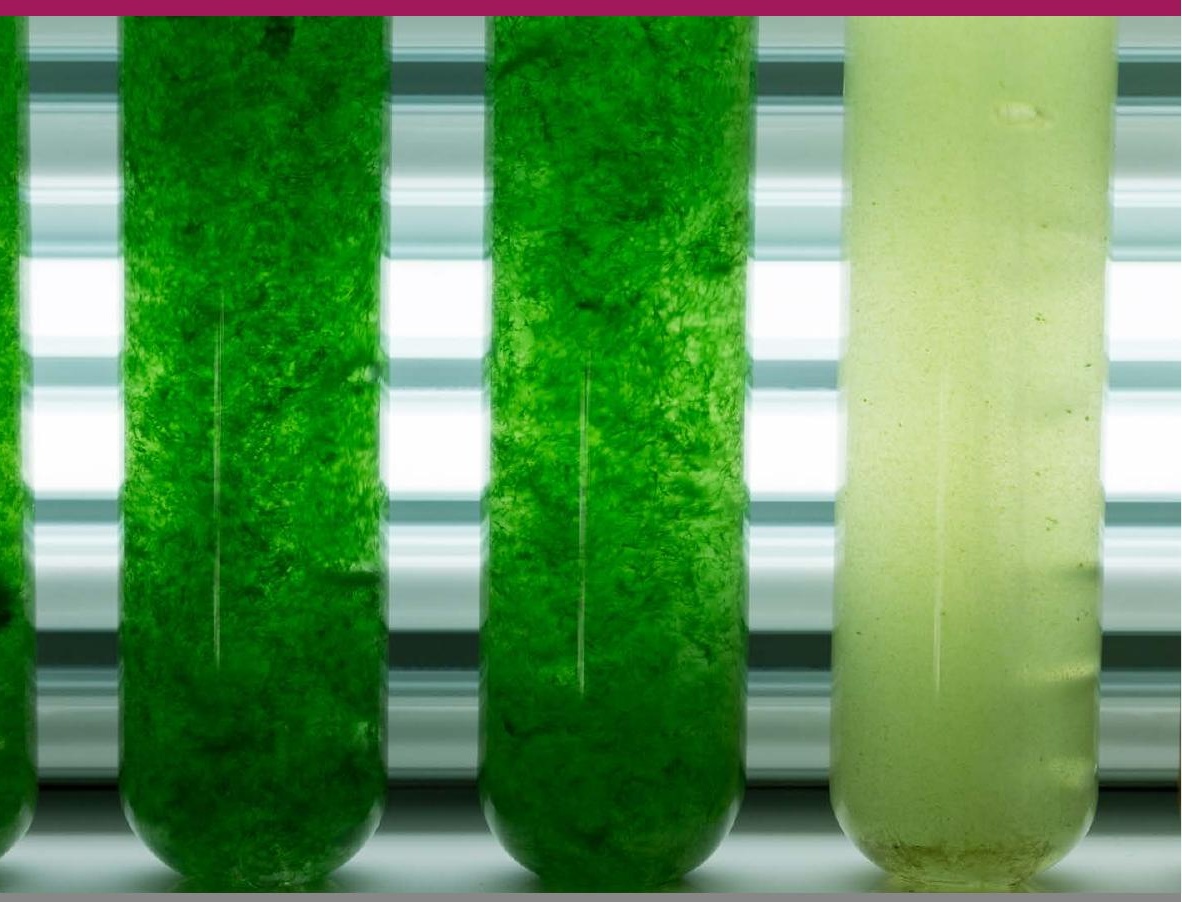




\section{Environmental impacts of seaweed cultivation: kelp farming and preservation}

Jean-Baptiste Thomas, KTH Royal Institute of Technology, Sweden; José Potting, EnviroSpotting, The Netherlands and KTH Royal Institute of Technology, Sweden; and Fredrik Gröndahl, KTH Royal Institute of Technology, Sweden

1 Introduction

2 LCA methodology

3 Case study: the Seafarm life cycle assessment

4 Overall impacts of the supply chain

5 Environmental impacts of a kelp juvenile hatchery

6 Environmental impacts of kelp cultivation

7 Environmental impacts of preservation: to dry, freeze or ensile?

8 Conclusion

9 Limitations of LCA

10 Future trends in seaweed-related LCA

11 Where to look for further information

12 References

\section{Introduction}

Seaweeds have a long history of use as food, feed and fertiliser. More recently, extracts from seaweed have also appeared in dyes, toothpastes, cosmetic creams and a range of other products. There is a fast-growing interest in seaweeds as an environmentally sustainable alternative to terrestrial plants and fossil fuels (McHugh 2003; Van den Burg et al. 2018; Van Hal et al. 2014). In Europe, a number of pilot projects and start-ups are exploring the potential of seaweed farming, preservation and processing, and novel seaweed applications that can substitute more carbon-intense or unsustainable fossilor terrestrial biomass-based products (see other chapters in this book). The supposed environmental sustainability of seaweed farming, preservation and processing is the subject of remarkably little research. Seaweed farming is taken to include all processes, from hatchery through marine cultivation to harvesting the seaweed. 
When talking about the environmental sustainability of seaweed, one must distinguish between two types of environmental impacts. The first relates to the environmental impacts of seaweed farming on the immediate marine environment, for example, the possible effects from the presence of infrastructure or the effects on local biodiversity. This type of impact is covered elsewhere in this book. The second type refers to the overall environmental impacts resulting from the whole seaweed supply chain, including all material and energy inputs that are used in order to produce specific seaweed products. This chapter focuses on the latter and how these impacts can be quantified by means of the life cycle assessment (LCA).

This chapter provides an overview of the environmental impacts of the supply chain for preserved seaweed. The supply chain includes the hatchery, marine infrastructure, deployment of juveniles and monitoring during cultivation (grow-out of seaweed), harvest, transport back to shore and preservation of the biomass. Not specifically addressed are the environmental impacts from downstream processing of the preserved biomass into a multitude of products, the utilisation of these products and their end-of-life disposal. However, they are discussed in light of the available literature. The environmental impacts of this further processing may or may not exceed the environmental impacts in the preceding supply chain. This will depend on the specific product and the processes involved in its manufacture.

The chapter starts with a short overview of the LCA methodology, and how it can be used to quantify the environmental impacts of seaweed supply chains. The next section introduces the 'Seafarm-LCA' taken from Thomas et al. (2021) as a case study for illustrating the environmental impacts of the preserved seaweed supply chain. Figures are based on the study published in the ICES Journal of Marine Science. Section 4 focuses on the overall environmental impacts of the preserved seaweed supply chain, in contrast to Sections 5-8 which focus on specific life cycle stages. Section 5 deals with spore preparation and seeding of juvenile seaweed onto the string in the hatchery, Section 6 goes into seaweed cultivation and harvesting, and Section 7 covers the preservation and storage of harvested seaweed. Each stage also includes the environmental impacts of the production of the equipment needed in that stage (i.e. the environmental impacts of cradle-to-equipment production). The chapter ends with a summary (Sections 8-9), followed by future trends in research (Section 10) and some suggestions for sources of further information for the interested reader (Section 11).

\section{LCA methodology}

LCA is a well-established approach to investigate the environmental performance of product systems and service systems (Baumann and Tillman 
2004), both referred to as product systems in the rest of this chapter. A core characteristic of systems is that they serve a function (Meadows 2015). LCA quantifies the environmental impacts per unit of function served by the product system, that is, per functional unit (Baumann and Tillman 2004; ISO 14044 2006), and not for a unit of product as is commonly miscommunicated.

The functional unit for a product system is typically based on its output, for example, 'one ton of dried seaweed meeting certain quality requirements', but it can sometimes also be based on system inputs (see Fig. 1). The latter is typically the case for 'waste-LCAs' comparing different types of waste treatment (Laurenti et al. 2014) but also applies to the case study LCA used for illustration in this chapter, for which the functional unit is 'one ton of freshly harvested kelp to be preserved'. This input-based functional unit enables the comparison of different methods of preserving kelp, with the rest of the compared product system being the same (Thomas et al. 2021). A further discussion of the functional unit aspects of LCAs is available in Sills et al. (2020), presented in the context of LCAs of algal biorefineries.

Many, if not most LCAs, indeed compare product systems, such as comparing a reference product system with an improved version of itself or, alternatively, comparing very different product systems with the same function. Comparative LCAs are typically performed to inform decision-makers, for instance within the industry, about whether to produce chemicals using one form of energy or another (Lammens et al. 2011), or to inform consumers choosing between seaweed burgers and conventional hamburgers (Van den Burg et al. 2018). Other LCAs typically focus on a single product system, usually to gain insights into environmental impact hotspots and to identify opportunities for optimisation.

A full LCA or 'cradle-to-grave' LCA covers a product system from raw material extraction, through materials production, product manufacture and use, up to and including processing the discarded product. Each of these so-called life cycle stages in a product system may (and often do) encompass more than one process. The production of woollen fabrics, for example, covers yarn spinning and fabric weaving, with several refining processes, both in between and following the spinning and weaving (Potting and Blok 1995).

While 'cradle-to-grave' LCAs encompass full product life cycles, many LCAs cover partial product life cycles. The waste-LCAs previously mentioned represent 'gate-to-grave' LCAs, where the 'gate' often is the entrance into the waste collection process (Laurenti et al. 2014). Other partial LCAs represent 'cradle-to-gate' LCAs, including the case study LCA in this chapter (see Fig. 1), where materials or substances are to be further processed after they exit the 'gate'. There are also 'gate-to-gate' LCAs, like a comparative LCA by KouchakiPenchah et al. (2015) for particleboard produced from agricultural and industrial waste residues. 

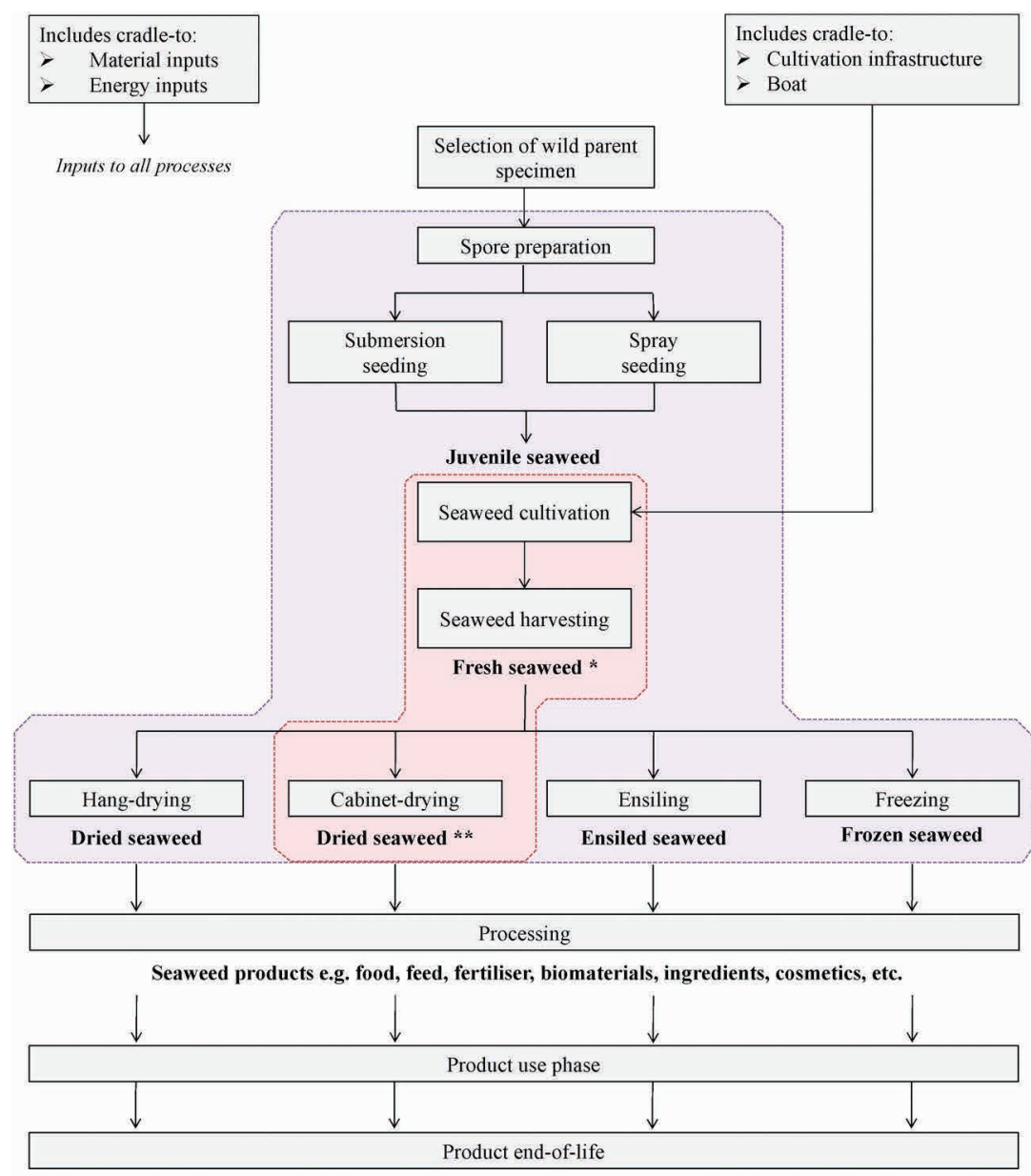

Van Oirschot et al, 2017

Thomas et al. 2020

Figure 1 An overview of the 'cradle-to-gate' product system, or supply chain, for preserved brown seaweed (i.e. kelp or Saccharina latissima). The figure exemplifies the two related input-based (single asterisk *) and output-based (double asterisk **) functional units.Source: the figure has been modified from Thomas et al. (2021).

An LCA should cover more than one process as well as more than one environmental impact, according to the ISO 14044(2006). Typical environmental impacts covered by LCAs are resource depletion, global warming, (stratospheric) ozone depletion, acidification, eutrophication, (tropospheric) photochemical ozone creation, human toxicity and ecotoxicity (Baumann and Tillman 2004). Life cycle studies covering just one environmental impact are not strictly LCAs, but rather footprint analyses (like carbon footprints), although 
they are nevertheless often referred to as LCAs. An example is a comparative 'LCA' by Taelman et al. (2015) of the cumulative exergy extraction from the natural environment of two seaweed cultivation infrastructures or a comparative 'LCA' by Alvarez-Hess et al. (2019) for the greenhouse-mitigation potential of 3-nitrooxypropanol and nitrate to cattle in cattle feeding.

The ISO-14040 series, notably the ISO 14044 (2006), provides the procedure for performing an LCA. An LCA consist of four phases:

1 Goal \& scope definition, which specifies why and how an LCA is performed.

2 Inventory analysis, which quantifies all environmental and economic inputs and outputs for all processes in a product system.

3 Impact assessment, which converts all environmental inputs and outputs, from inventory analysis to a range of environmental impacts.

4 Interpretation, which evaluates the results of inventory analysis and impact assessment against the background of the defined goal \& scope, in order to draw conclusions.

These are discussed below.

Goal \& scope definition is the most important phase of an LCA, as it sets out how the other three phases are to be executed. In this first phase, all selected methodological choices and assumptions are primarily based on their appropriateness in answering the research questions at hand. This notably applies to defining the functional unit (in terms of which impacts will be expressed), delineation of the product system, choice of inventory methods and data for inventory analysis (e.g. allocation procedures and data requirements), impact assessment (e.g. impact categories and characterisation methods) and interpretation.

The ISO 14044 (2006) does not provide the actual methodology for performing an LCA, but there are a couple of handbooks providing detailed guidance. These handbooks are often made on behalf of a regional government. A widely used handbook is the one from the European Union, describing the so-called ILCD-methodology (ILCD 2010). Such handbooks often are of a technical character (e.g. Guinée 2002). An accessible handbook on LCA, albeit slightly outdated, is still the Hitch Hiker's Guide to LCA by Henrikke Baumann and Annemarie Tillman (2004). However, one can easily find a more recent alternative by searching online for 'LCA' and 'textbook'.

\section{Case study: the Seafarm life cycle assessment}

\subsection{Choice of case study}

One of the critical challenges in the LCA is a lack of available information to compile reliable and case-based inventory data across whole product life 
cycles. Good quality inventory analysis data is particularly difficult to obtain for seaweed product systems. This is particularly the case for the cultivation, manufacturing and subsequent life cycle stages, which are still evolving in an industrial context in Europe.

Many of the seaweed-related LCA studies in the literature focus on hypothetical production systems and limited experimental data (e.g. Langlois et al. 2012; Alvarado-Morales et al. 2013; Aitken et al. 2014; Czyrnek-Deletre et al. 2017; Van Oirschot et al. 2017; Parsons et al. 2019). Some studies also use data from pilot facilities (e.g. Taelman et al. 2015; Jung et al. 2017; Vijay Anand et al. 2018) and extrapolate potential future large-scale production systems (e.g. Seghetta et al. 2016, 2017). Inventory data are often based upon a mix of literature and personal communications, or partially based on data from case studies, experiments or established farming practices covering all processes from the hatchery through to marine cultivation to seaweed harvesting. The earliest LCA studies on seaweed product systems, such as that by Langlois et al. (2012), which itself is based on a hypothetical system, therefore form the foundation of the literature upon which many of the subsequent studies are based.

The Thomas et al. (2021) seaweed LCA study is, to our knowledge, the only one featuring inventory analysis wholly based on reliable data from a commercial operation, including detailed descriptions of kelp farm operations and a detailed inventory of activities, thus ensuring a high degree of certainty with respect to the life cycle inventory. These case data originate from the Seafarm project (www.seafarm.se) and are updated in line with optimised practices as established by Nordic Seafarm AB (formerly Koster Alg AB). The study of Thomas et al. (2021) is delimited to a cradle-to-gate perspective (where the gate is the production of preserved seaweed), to focus the assessment on those parts of the product system that are well established and from which high-quality data can be obtained. The rest of this chapter is largely based on the results from Thomas et al. (2021).

\subsection{The Seafarm project}

Five Swedish universities have worked together on the Seafarm project to develop a sustainable system for farming and processing seaweeds, in particular kelp (the brown seaweed Saccharina latissima). The end-of-project conference in June 2020 was delayed owing to the COVID-19 pandemic. Therefore, at the time of writing this chapter, the Seafarm project had not yet officially ended, but most of its research activities had been completed (Potting et al. submitted).

For research purposes, the Seafarm project was developed at a farming site on Sweden's west coast (see Fig. 2). This included a trial hatchery, cultivation, harvesting and processing operations (e.g. a biorefinery), to study both the 
commercial viability and the environmental impacts on the local ecosystem. The Seafarm project thus aimed to lay the foundations for a future Swedish seaweed industry. The project also broke new ground in addressing associated regulatory and licensing hurdles, which had stalled progress on a previous project (e.g. BioMara in Scotland). The project consisted of four research Focus Areas (FA) looking into specific parts of the supply chain, centred around a fifth FA. This fifth FA was strategically leading and connecting the four other FAs through a transdisciplinary sustainability assessment (Thomas 2018). The LCA by Thomas et al. (2021) formed a key part of this sustainability assessment.

The LCA by Thomas et al. (2021) serves to illustrate the environmental impacts of the supply chain for preserved seaweed (i.e. excluding downstream processing into products derived from seaweed). This section provides details of the cultivation system employed in the Seafarm project, to provide readers with a deeper understanding of how the LCA results in the case study may relate to different seaweed supply chains. The subsequent supply chain stages covered by the case study (see Fig. 1) are described in more detail in later sections. Readers should refer to Thomas et al. (2021) for full details of the precise methodology and data used in the case study LCA.

The cultivation system employed for the Seafarm project is located in the Kosterhavets National Park along the Skagerrak coast, within $5 \mathrm{~km}$ of the Sven Lovén Centre for Marine Sciences in Tjärnö, which is a part of the Gothenburg University. Many of the practical aspects of seaweed farming take place there. The key stages range from the cultivation, preparation, monitoring, harvesting, maintenance, the deployment of the hatchery-producing strings seeded with

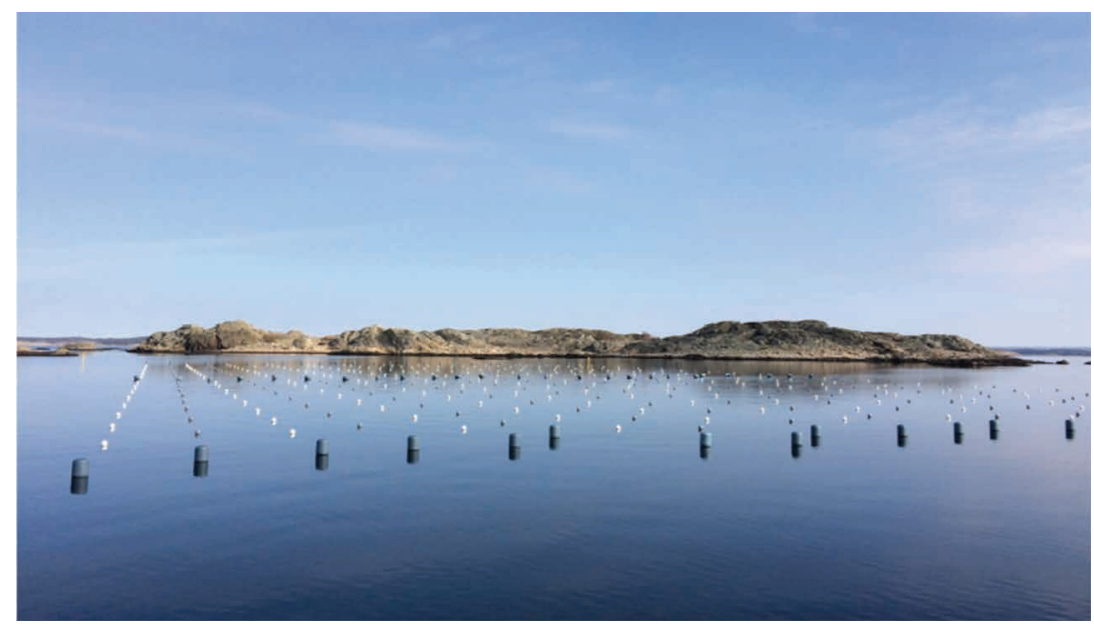

Figure 2 Seafarm-cultivation in the Kosterhavets National Park, Spring 2017 (photo: Gunnar Cervin \& Göran Nylund). 
juvenile kelp on longlines at sea and the housing of materials. The system covers 2 ha with nearly $5 \mathrm{~km}$ of conventional longline cultivation infrastructure, that is, longlines at circa $1 \mathrm{~m}$ depth kept in place by anchors and buoys (see again Fig. 1; for a complete description of the cultivation system, see Fig. 2 in Thomas et al. 2021).

In late summer, specimens of the brown seaweed Saccharina latissima, known as sugar kelp, are collected from the local environment (i.e. from the local gene pool), and brought back to the hatchery facility at Tjärnö. Over the following months, the kelp's reproductive cycle is triggered and juveniles settle on seeded strings (commonly also referred to as collectors). Once the juveniles have become established in late autumn, the seeded strings are deployed on longlines at sea (see Fig. 3). Over the following months, the cultivation site is monitored on a regular basis.

Most of the mature kelp is then harvested between early April and late May. The longlines are raised mechanically onto a harvesting barge. Beyond this harvest window, the kelp can become spoilt by epiphytic growth. During this harvest window, kelp individuals can more than double in size and undergo important changes in structural and biochemical composition (Thomas et al. submitted). In early April, one might expect to harvest around $5 \mathrm{~kg} \mathrm{~m}^{-1}$ longline of smaller, thinner kelp specimens, whereas up to $15 \mathrm{~kg} \mathrm{~m}^{-1}$ longline of larger, thicker kelp specimens can be harvested in May. This equates to a yield potential ranging 12.5-37.5 tons FW ha ${ }^{-1}$. Early and late-harvested kelp may be more or less suitable for various end uses (Thomas et al. submitted; Vilg et al. 2015). This whole process is repeated every year, from the selection of parent specimen to harvesting.

After being harvested at sea and returned to land, kelp requires processing without delay to avoid decay and to preserve the biomass in a stable state that is practical for both transport and subsequent refining into products. At harvest, the fresh biomass contains approximately $84.9 \%$ of dry matter (Thomas et al. 2021), though this can vary to a large extent (Thomas et al. submitted). As a part of the Seafarm project, several alternative preservation approaches were trialled. Trials included hanging the biomass on wooden frames to dry outdoors (Fig. 8), drying the biomass indoors in hot air cabinets, ensilage experiments at the laboratory scale and freezing the biomass in a shipping container. Initially, only the freezing was conducted on a large scale, but later on in the project, large-scale drying methods were developed. Data in Thomas et al. (2021) are representative of larger-scale biomass preservation following scaled adaptations of these four preservation methods.

\section{Overall impacts of the supply chain}

Figure 4 and Table 1 give an overview of the overall environmental impacts of the seaweed supply chain, from Thomas et al. (2021), up to and including 

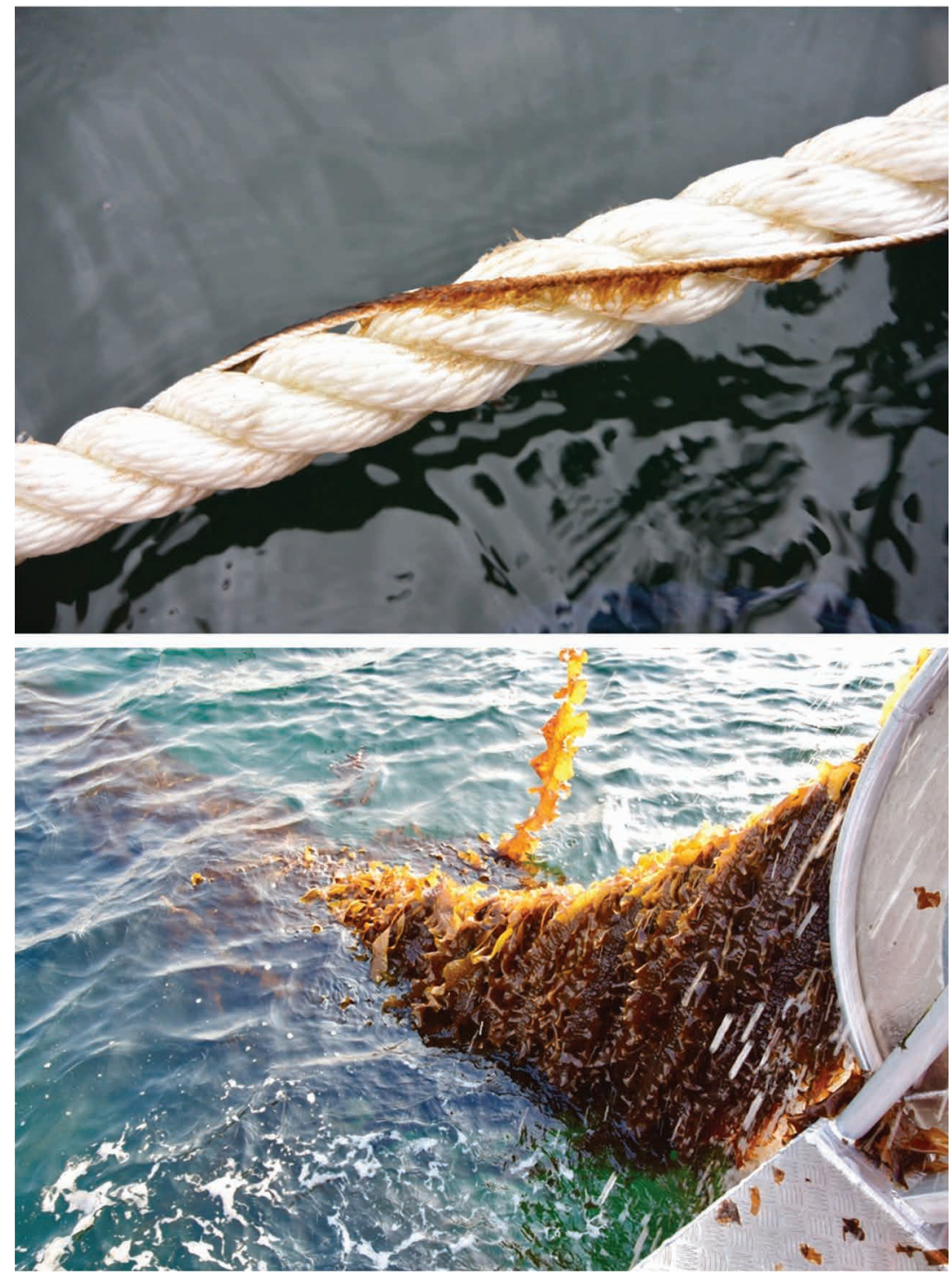

Figure 3 Above: seeding-line of juvenile Saccharina latissima being deployed on a longline at the Seafarm cultivation site in autumn 2015 (photo: Gunnar Cervin \& Göran Nylund). Below: harvesting the mature Saccharina latissima from a longline in April 2019 (photo: Jean-Baptiste Thomas).

the preservation of freshly harvested seaweed. The differences between the four preservation methods are depicted in Fig. 4, by expressing the impacts of the overall seaweed supply chain relative to the impacts of the worstperforming preservation method (freezing). Overall, the preservation of the 
freshly harvested seaweed (specifically using freezing or hot air cabinet drying) and the cultivation process (including the system infrastructure) are the two most important processes in terms of impacts. The freezing and hot air cabinet drying methods documented in Thomas et al. (2021) both consume a lot of energy (especially the former) in the course of the 90 days of storage used in the study (see Section 8). The impacts of the cultivation and harvest stages are dominated by the physical infrastructure at sea (see Section 6).

The impacts of the hatchery processes (spore selection and seeding) are relatively small compared to the rest of the supply chain (see Section 5). The two other preservation methods, hang-drying and ensiling, require relatively little energy and material inputs when compared to hot air cabinet drying and freezing, and so have a much reduced environmental impact per ton of preserved kelp (see Section 7). These differences mean that, in practice, overall impacts can vary by more than $50 \%$ (on average across all impact categories), depending on which preservation method is selected.

The overview in Fig. 4 also includes some environmental impact mitigation credits (bars below $0 \%$ on the $y$-axis) resulting from carbon and nutrient assimilation in kelp during its cultivation and the associated impact mitigation (see Section 6.3 for more details). Note that this study stops at the gate (the preserved biomass) and does not include downstream emissions when the biomass is processed into products and consumed. However, if the study were to include the processing and use of the kelp, one might argue that the assimilated nutrients and carbon would presumably be released again as emissions when kelp products are consumed. This also applies to the small environmental impact mitigation credits allocated for the co-production of biogas from ensilage effluents. These impact mitigation credits are further discussed in Section 6.2.

The overview in Fig. 4 relates to the case study LCA by Thomas et al. (2021), but other studies in the literature report similar results (Aitken et al. 2014; Taelman et al. 2015; Van Oirschot et al. 2017). These studies also identify cultivation infrastructure and processing of the biomass as impact hotspots. The parallel is not surprising in the case of Van Oirschot et al. (2017), given that the study utilises similar data from the Seafarm project. Aitken et al. (2014) is based on different case data, though the same impact assessment method (CML 2001) is used as in both Van Oirschot et al. (2017) and Thomas et al. (2021).

Although they are based on different situations, studies using other LCA impact assessment methods still come to similar results. Taelman et al. (2015), for instance, compares two cultivation infrastructures by their cumulative energy extraction from the natural environment (CEENE). They also identify cultivation infrastructure as a dominant contributor in both cases, although they both also identify boat fuel consumption as a significant contributor (a finding further discussed in Section 6). In the studies by Seghetta et al. (2016, 


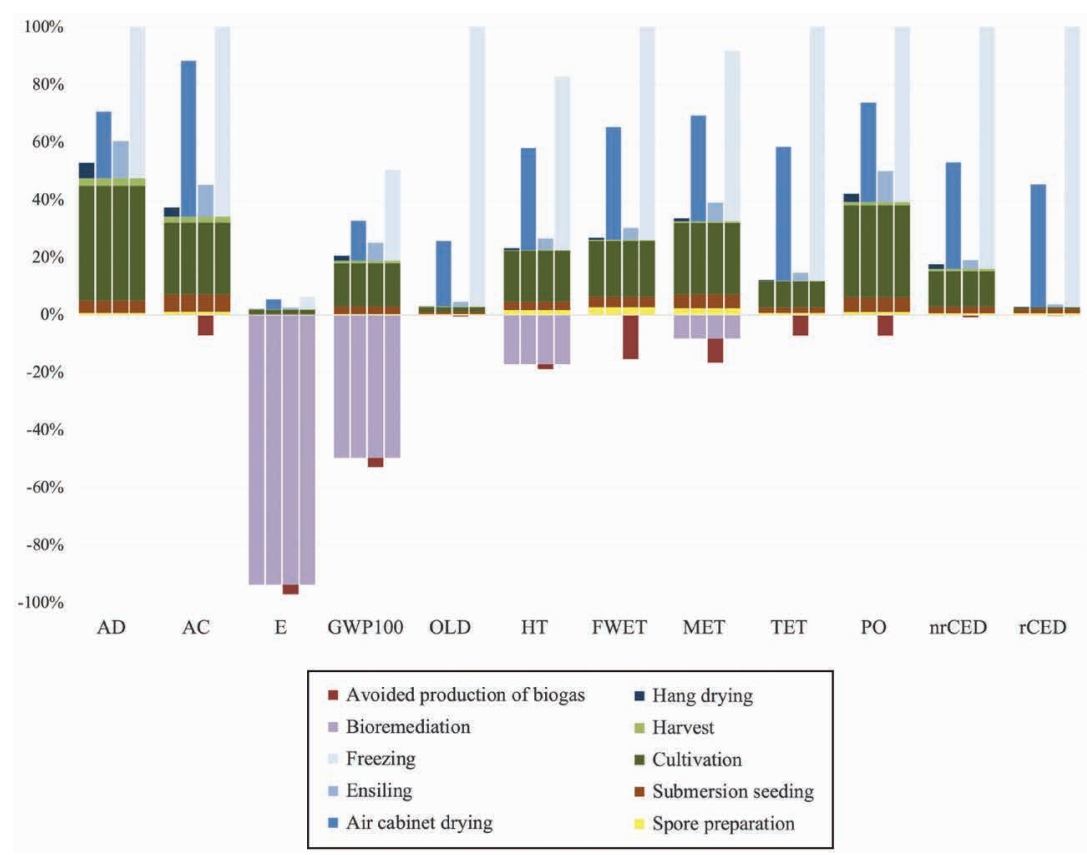

Figure 4 An overview of the environmental impacts of the preserved seaweed supply chain, highlighting the contributions from the main steps of the process chain and comparing the four ultimate preservation methods: hang drying, air-cabinet drying, ensiling and freezing. The graph also shows the impact mitigation credits accorded for bioremediative effects of kelp cultivation (i.e. carbon and nutrient assimilation), and impact mitigation credits accorded to the ensilage co-products, the ensilage effluents, which are used to for biogas production. Figure 4 is supported by Table 1, which includes the numeric values for impacts as expressed per ton fresh weight. The impacts are expressed across 10 impact categories of the CML baseline method: abiotic depletion (AD), acidification (AC), eutrophication (E), climate impact (GWP100), ozone layer depletion (OLD), human toxicity $(H T)$, fresh water ecotoxicity (FWET), marine ecotoxicity (MET), terrestrial ecotoxicity (TET) and photochemical oxidation (PO). These are complemented by 2 additional categories showing Cumulative Energy Demand from non-renewable ( $n r C E D)$ and renewable (rCED) sources. Source: figure modified from Thomas et al. (2021).

2017), the ReCiPe impact assessment method is applied and complemented by additional impact categories (e.g. USEtox). In both of those studies, the cultivation infrastructure is also identified as a critical hotspot.

To better understand the opportunities for environmental optimisation of supply chains for preserved seaweed, one must dig into each of the stages of the supply chain and look at contributions resulting from specific system components. Seaweed cultivation and downstream processing (e.g. preservation) being the two most influential processes in the product system, provide the greatest opportunities for environmentally optimising the supply 


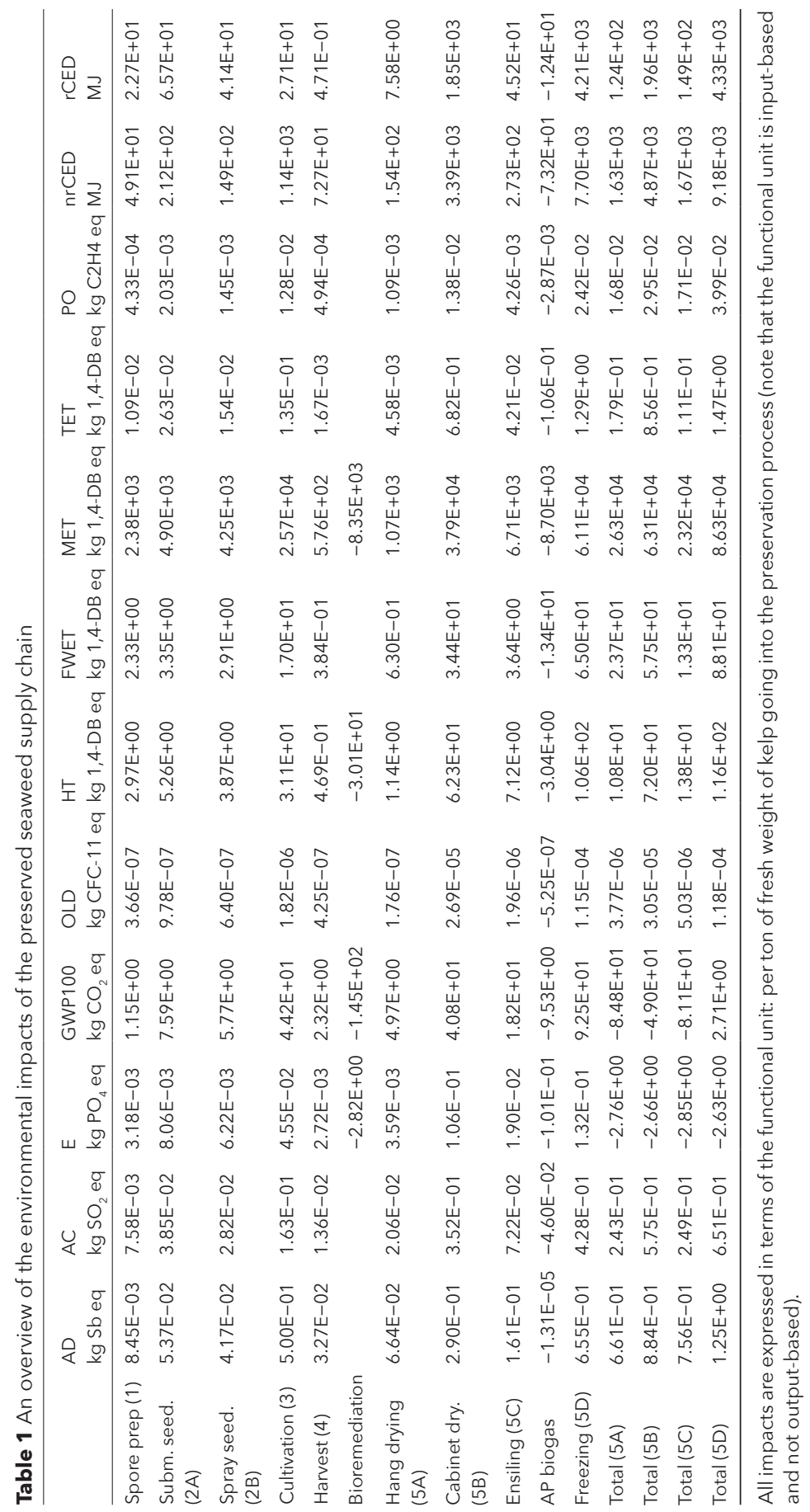


chain for preserved seaweed. The following sections of this chapter cover all the life cycle stages of the Thomas et al. (2021) case study in detail, starting with the hatchery process (Section 5), then the cultivation stages (Section 6) and finally the preservation stages (Section 7).

\section{Environmental impacts of a kelp juvenile hatchery}

The hatchery process, which provides juvenile seaweed that can be deployed at sea, involves spore preparation and seeding processes. As Fig. 4 shows, these processes contribute little to the overall environmental impacts of the preserved seaweed supply chain in the case study LCA. On average, across all impact categories, the combined hatchery processes contribute to around $5 \%$ of the impacts of the supply chain. Improving the environmental performance of hatchery processes will not, therefore, substantially reduce the overall environmental impacts of the supply chain. However, this does not mean that environmentally optimising this process is irrelevant.

In Thomas et al. (2021), the hatchery is split into two stages. First, the spore preparation process accounts for the activation of the reproductive cycle and the acquisition of a concentrated spore solution from parent specimens. Second, two alternative seeding processes, called submersion seeding and spray seeding, are compared, following the assumption that both produce seeded lines of identical quality (ready to be deployed to sea). The main difference between these processes relates to the stage of the kelp's reproductive cycle at which the settling on the strings occurs. For submersion seeding, this occurs during the formation of sporophytes, while for spray seeding, gametophytes are sprayed onto the collectors.

Figure 5 provides a comparison of the environmental impacts resulting from (a) submersion seeding and (b) spray seeding, including the impacts of all equipment, energy and materials used. On the whole, it is clear that submersion seeding performed slightly worse than spray seeding. This is due to the fact that, in practice, submersion seeding takes a little longer than spray seeding. The resulting time savings for the spray seeding approach convert to slightly reduced energy consumption and thus to slight reductions in the environmental impacts across all categories.

The energy used in the sub-processes, based on the electricity mix used in Sweden (predominantly hydro and nuclear energy), notably the energy used in temperature control (or cooling) and lighting, are the dominant factors in the environmental impacts of the hatchery. This suggests that hatcheries should, as much as possible, utilise energy-efficient temperature control and lighting systems in order to minimise environmental footprints. In terms of material contributions to impacts, the main contributors to the hatchery process were found to be the acrylic Perspex aquaria and the nylon seeding lines. Further 


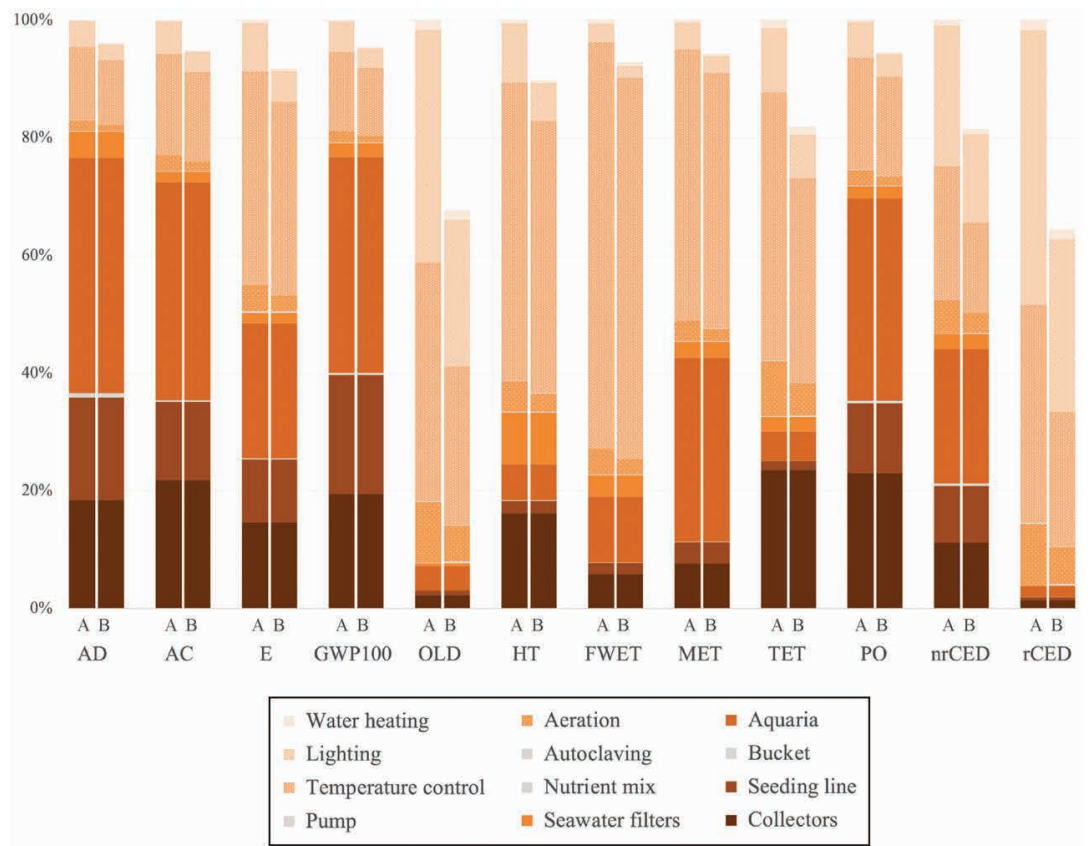

Figure 5 The breakdown of the environmental impacts of the two alternative seeding processes in the hatchery - (a) submersion seeding and (b) spray seeding - showing the relative contributions of sub-processes to highlight impact hotspots. The impacts are expressed across 10 impact categories of the CML baseline method: abiotic depletion (AD), acidification (AC), eutrophication (E), climate impact (GWP100), ozone layer depletion (OLD), human toxicity $(H T)$, fresh water ecotoxicity (FWET), marine ecotoxicity (MET), terrestrial ecotoxicity (TET) and photochemical oxidation (PO). These are complemented by 2 additional categories showing Cumulative Energy Demand from non-renewable ( $n r C E D)$ and renewable (rCED) sources. Source: the figure has been modified from Thomas et al. (2021).

reduction of impacts might therefore be made by identifying lower-impact alternatives to these materials. These findings are generally supported by LCA literature of microalgae photobioreactors, for example, in Porcelli et al. (2020) and Ketzer et al. (2017), which show that energy use, as well as the use of plastics and other materials, typically dominates the impact profiles.

The impacts of the spore preparation stage are not included in Fig. 5, as this step only results in a fraction of the impacts of the seeding methods. Spore preparation also utilises similar materials and systems as the seeding stages, although the energy requirements are much lower. As a result, any optimisation implemented in the seeding processes will also affect the spore preparation stage.

In addition to the impact hotspots and opportunities for environmental optimisation mentioned above, one additional aspect can multiply impacts 
from the hatchery. This is the overall failure of the hatchery to deliver highquality seeded lines. Hatchery failure can be due to a number of reasons, for example, the contamination by epiphytes or bryozoans as the juveniles mature. The consequences can be severe in terms of life cycle impacts. A failure will result in the need to re-attempt the hatchery processes, resulting in additional energy requirements in the second attempt.

Hatchery failure can also delay the deployment of juveniles to sea by several months. Recent research has suggested that earlier deployments can help to increase the biomass yields at harvest (Handå et al. 2013; Thomas et al. submitted); thus a later deployment from a failed hatchery can also result in decreased yields. This, in turn, would translate to a relative increase in impacts, particularly if the functional unit (in terms of which the impacts are expressed) relates to productivity, for example, per ton of fresh kelp.

On the whole, therefore, though the overall contributions to environmental impacts by the hatchery stage are small, hatchery activities can still have an important effect on the overall supply chain impacts in the event of hatchery failure. The results from Thomas et al. (2021) point towards the deployment (to sea) of high-quality seeded lines in early autumn as one of the most important variables to minimise the life cycle environmental impacts of the production of preserved kelp. Optimisation strategies, therefore, should reduce energy and material requirements where possible, without compromising the production of high-quality seeded-line hatchery techniques.

\section{Environmental impacts of kelp cultivation}

As mentioned in Section 1, when talking about the environmental sustainability of seaweed, one must distinguish between two types of environmental impacts: the impacts on the immediate marine environment (covered elsewhere in this book), and the impacts resulting from all material and energy inputs of the system, also referred to as life cycle impacts. This section addresses the latter, that is, the life cycle environmental impacts of kelp cultivation. Section 6.1 discusses the environmental impacts of longline-cultivated kelp based on Thomas et al. (2021) and compares it to other kelp LCAs. Section 6.2 discusses the impacts of harvesting the mature kelp and discusses the key related factors that affect impacts, for instance, factors relating to fuel consumption. Section 6.3 discusses the cradle-to-gate environmental impact mitigation resulting from the assimilation of carbon and nutrients in the kelp.

\subsection{Environmental impacts of longline cultivation infrastructure}

The seaweed cultivation infrastructure featured in the case study LCA is a standard longline system located at a semi-sheltered site, developed as part of the Seafarm project (see Fig. 2). The seaweed cultivation infrastructure 
consists of 26 polyester silk longlines of $190 \mathrm{~m}$, kept at a depth of $2 \mathrm{~m}$ by polyvinyl chloride buoys with connecting polypropylene ropes situated every $10 \mathrm{~m}$ along their whole length. An anchoring polyethylene buoy at the end of each longline maintains strong buoyancy via a thick and strong polypropylene rope, a low-alloy steel chain and a low-alloy steel shackle fixed to a concrete anchor on the seafloor. The 26 longlines run parallel to one another with $4 \mathrm{~m}$ of access corridor in-between. Another polyester silk longline runs laterally across the midpoints of each longline, to provide additional structural reinforcement. This lateral longline is also held in place by anchoring buoys connected to concrete anchors with thick ropes, chains and shackles. Further details on the life expectancies of each item can be found in Thomas et al. (2021).

Figure 6 shows a breakdown of the life cycle environmental impacts of the material and energy inputs required to build, install, operate and harvest a cultivation rig at sea. The results show distinct similarities with other studies. The ropes, and specifically the polyester silk longlines, are mainly responsible for the impacts across most impact categories, most notably the abiotic depletion and non-renewable cumulative energy-demand categories. These significant impact contributions are due to two contributing factors. The first is that collectively, the longline ropes (which are $16 \mathrm{~mm}$ in diameter) are the main material inputs of the system by mass (excluding the concrete anchors). The second contribution is that a considerable amount of non-renewable (fossil) resources are consumed in the production of the polyester silk ropes.

Another evident impact hotspot visible from Fig. 6, most notable for the toxicity categories, is the impact contribution of the galvanised steel chains. The important impact contribution of the chains was also identified in Van Oirschot et al. (2017), though that study features the use of stainless steel (chromium alloy) chains with impacts considerably worse than those of the galvanised steel chains used in the present case study. In addition to the ropes and chains, the combined remaining material inputs to the cultivation stage of the life cycle (buoys, anchors and shackles) account for approximately 20\% of the impacts on average across all impact categories. Finally, the monitoring of the site by means of return trips using a dinghy, and the initial transport and installation of the cultivation infrastructure, together represent only a minor share of the impacts - at less than $10 \%$ on average across all impact categories.

A key environmental optimisation opportunity therefore lies in finding lower-impact alternatives to these ropes and chains. Taking into account the number of cultivation cycles, either rope alternatives manufactured from durable bio-based materials and suitable for this type of marine application could be identified, or thinner ropes might be utilised to reduce total material inputs and thus reduce impacts. To reduce the impacts from chains, research is 


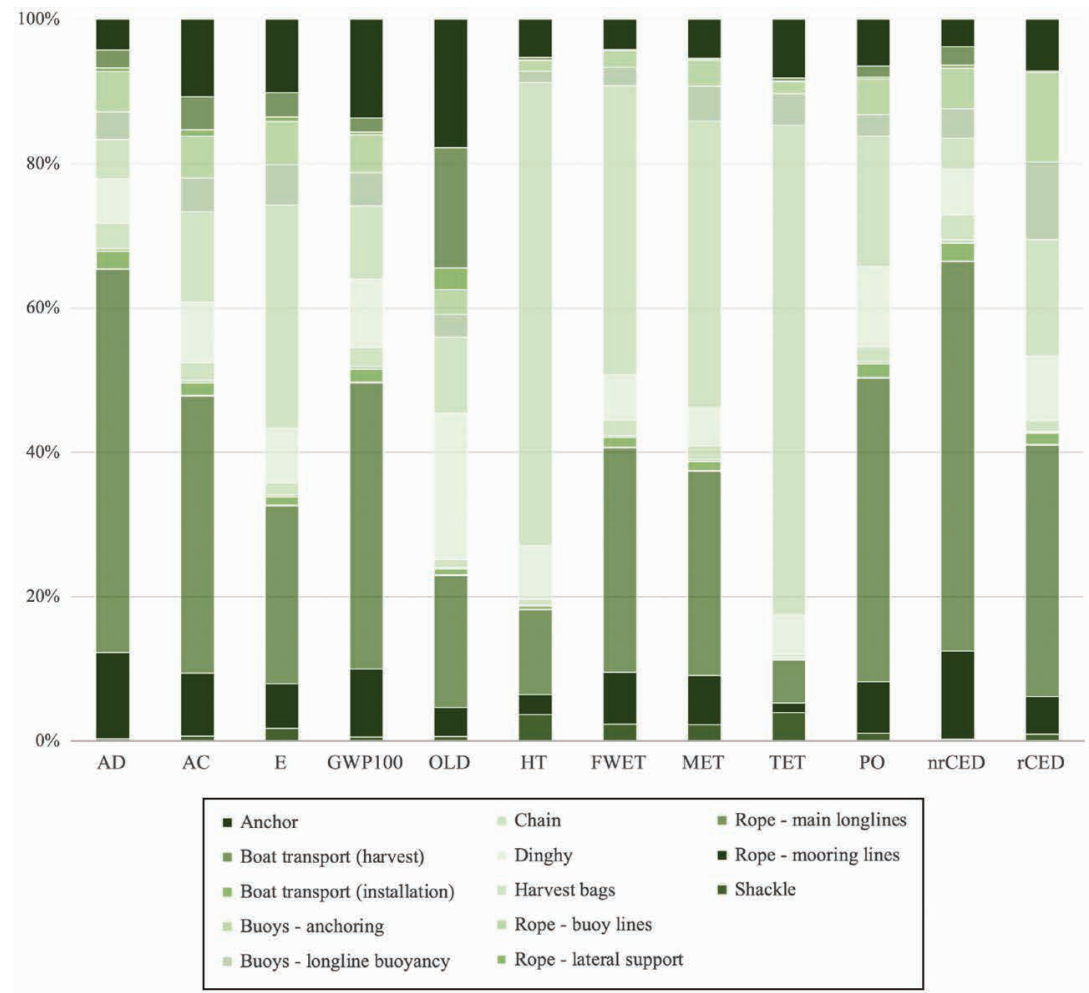

Figure $\mathbf{6}$ The breakdown of the environmental impacts of the cultivation and harvesting life cycle stages, showing the relative contributions of sub-processes to highlight impact hotspots. The impacts are expressed across 10 impact categories of the CML baseline method: abiotic depletion (AD), acidification (AC), eutrophication (E), climate impact (GWP100), ozone layer depletion (OLD), human toxicity (HT), fresh water ecotoxicity (FWET), marine ecotoxicity (MET), terrestrial ecotoxicity (TET) and photochemical oxidation (PO). These are complemented by 2 additional categories showing Cumulative Energy Demand from non-renewable ( $\mathrm{nrCED}$ ) and renewable (rCED) sources. Source data: the figure has been modified from Thomas et al. (2021).

needed to determine the feasibility of using chain-free infrastructure designs or to identify low-impact alternatives. Recycling these ropes and chains at their end-of-life may be another way to reduce their impact. Similarly, effective maintenance strategies should be developed to extend the life expectancy of these key infrastructural components.

It should be noted that most seaweed cultivation sites along the European and American coasts initially began as pilot sites. The primary concern of these pilots would have been to explore seaweed cultivation feasibility and infrastructure survivability, given local conditions. Many of those cultivation infrastructures, including the one in the case study LCA, are therefore likely 
to be over-engineered to ensure survivability. The design and construction of cultivation infrastructure should, of course, respect local marine conditions and other requirements. However, material and structural optimisation is also important, to optimise the economic and environmental viability of seaweed farming. Seaweed LCA literature contributes to these areas by highlighting the need for optimisation of the environmental performance of farm structures. Combining LCA approaches with survivability and cost-optimisation remain important areas for further research.

\subsection{Environmental impacts of harvesting}

The harvesting activities discussed in Thomas et al. (2021) are limited to the transport of the kelp from the cultivation site to a dock approximately $10 \mathrm{~km}$ away, and the harvest bags used to pack the seaweed as it is harvested. As can be seen from Fig. 6, together they account for less than $10 \%$ of the impacts on average across all impact categories. It should be noted, however, that this is principally due to the fact that the cultivation site is within a relatively close proximity to the dock (around $10 \mathrm{~km}$ ). Furthermore, the low-impact contribution of the boat transport may also be because the Ecoinvent database, from which boat impacts were exported, lacks impact data for small to medium-scale boat transportation at sea. In the Thomas et al. (2021) study, transport by motorised barge was selected and adjusted by adding the estimated fuel consumption.

In other LCA studies that involve marine transport, results often show that emissions from boat transportation represent significant impact hotspots. This may be because alternatives to Ecoinvent may have been used, different types of fuel were employed or longer transport distances were involved. LCA studies that have identified marine transport as an impact hotspot highlight the need to minimise marine transport distances or to utilise more efficient vessels. This has been highlighted as an area of notable uncertainty requiring further research.

\subsection{Impact mitigation by carbon and nutrient assimilation}

Environmental impact categories in LCA studies can be based on a range of metrics: primary energy demand and resource depletion or emissions to the environment of specific compounds and their equivalents. Climate impacts within the CML 2001 method, for instance, are measured in terms of kilograms of $\mathrm{CO}_{2}$-equivalent emissions, which include emissions of methane and other greenhouse gases, converted by equivalency factors to $\mathrm{CO}_{2}$ equivalents. Similarly, eutrophication impacts within the CML 2001 method are measured in terms of kilograms of $\mathrm{PO}_{4}$-equivalent emissions, which include emissions 
of nitrates, nitrogen and phosphorus converted by equivalency factors to $\mathrm{PO}_{4}$ equivalents.

In line with this methodology, LCA studies by Seghetta et al. (2016, 2017) were designed to take into account the biogenic carbon and nutrient assimilation by kelp, and their subsequent removal from marine environments as the kelp is harvested, an approach also followed by Thomas et al. (2021). This removal from marine environments is considered to be the opposite of emissions to those environments (i.e. an assimilation or an uptake). Carbon uptake is effectively an (indirect) uptake of atmospheric $\mathrm{CO}_{2}$ that has dissolved in marine environments as part of the marine carbon cycle (Duarte et al. 2017). Impact mitigation credits are therefore allocated for the removal of kelp from marine environments corresponding to the amounts of $\mathrm{PO}_{4}$ and $\mathrm{CO}_{2}$ equivalents contained in the harvested biomass.

This methodological approach applied to the Thomas et al. (2021) and Seghetta et al. $(2016,2017)$ studies yields similar results in both cases. In the case of Thomas et al. (2021), Fig. 4 shows that most of the carbon emissions from supply chain activities are counteracted by $\mathrm{CO}_{2}$-equivalent uptake by the biomass. Similarly, the eutrophication mitigation potential resulting from the uptake of $\mathrm{PO}_{4}$ equivalents far outstrips the emissions of $\mathrm{PO}_{4}$ equivalents from supply chain activities. These results therefore suggest that the production of kelp can (potentially significantly) mitigate local eutrophication, while providing a biomass raw material for the bioeconomy that performs well from a climate perspective.

\section{Environmental impacts of preservation: to dry, freeze or ensile?}

As mentioned in Section 3, when kelp is harvested, it requires rapid processing to stabilise and preserve the biomass. The four alternative approaches compared in Thomas et al. (2021) are based on scaled processes that were either trialled during the Seafarm project or that have become established practices. As can be seen from Fig. 4, and particularly in Fig. 7, there is a strongly diverging contribution of the four preservation methods to the overall environmental impacts of the preserved seaweed supply chain in the case study. In each impact category, freezing dominates the impact contributions, followed closely by air cabinet drying. The ensiling and hang-drying processes were found to have far lower contributions, primarily as these require little to no energy for their operation.

One key parameter separates these four preservation methods: energy consumption. Those processes with greater energy consumption typically also have larger impact contributions. It is important to note that, once ensiled or dried, biomass does not require constant energy inputs in order to keep it 


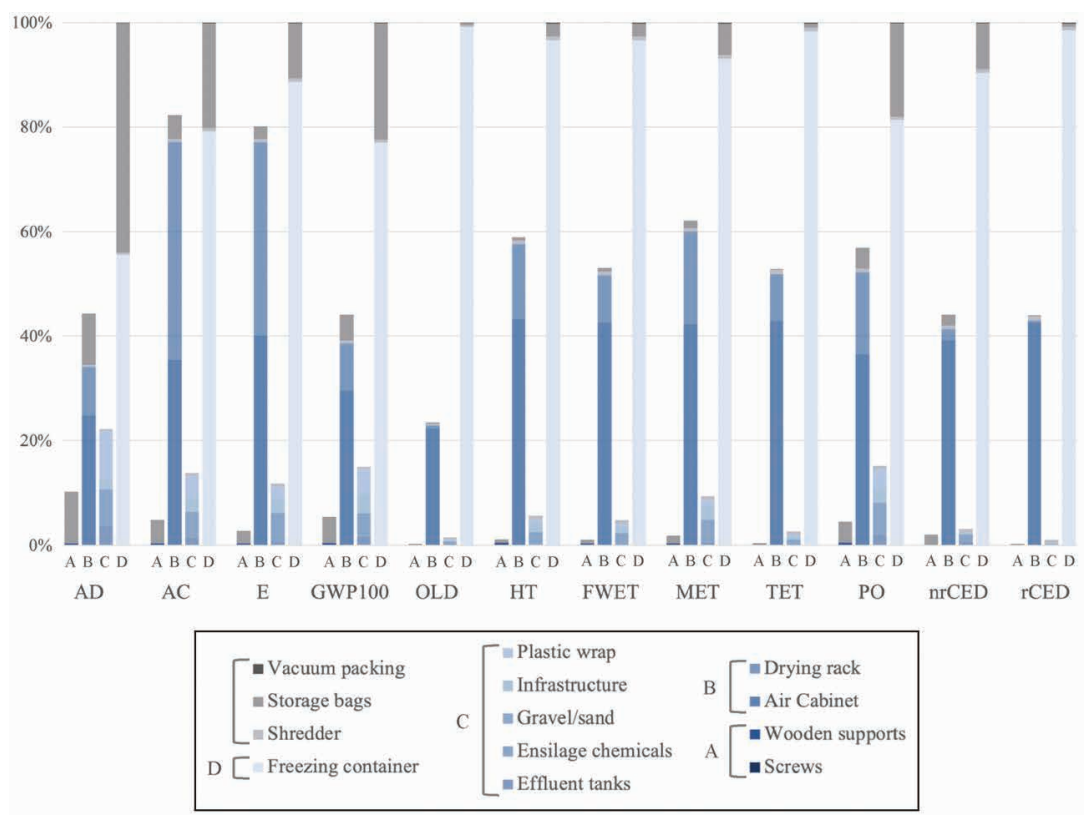

Figure $7 \mathrm{~A}$ comparison of the environmental impacts of the four alternative preservation methods, compared in Thomas et al. (2021): (a) hang drying, (b) air-cabinet drying, (c) ensiling and (d) freezing. The figure also presents a breakdown of the relative contributions of sub-processes for each preservation method, to highlight impact hotspots. The impacts are expressed across 10 impact categories of the CML baseline method: abiotic depletion (AD), acidification (AC), eutrophication (E), climate impact (GWP100), ozone layer depletion (OLD), human toxicity (HT), fresh water ecotoxicity (FWET), marine ecotoxicity (MET), terrestrial ecotoxicity (TET) and photochemical oxidation (PO). These are complemented by 2 additional categories showing Cumulative Energy Demand from non-renewable ( $n$ rCED) and renewable (rCED) sources. Source: the figure has been modified from Thomas et al. (2021).

preserved over time, whereas frozen biomass does require constant energy inputs to maintain cold storage. A storage time of 90 days (approximately three months) was used in Thomas et al. (2021), helping to explain why freezing has a much greater impact. This study highlights that frozen biomass should not be stored for extended periods unless in very efficient cold storage. However, whilst the production of frozen biomass had the worst performance, it also had the greatest variability.

Drying in an air cabinet was the second most energy-consuming process, and as can be seen from Fig. 7. The principal material input, stainless steel drying racks, also has a significant impact contribution in some of the impact categories, notably the acidification potential and eutrophication potential impact categories. It could be argued that this is an over-estimation, as in 
practice, such racks would be utilised for many purposes in the course of their life. However, they are assumed in the present study to have been exclusively built and used for this air cabinet drying method in the course of their estimated 10-year life expectancy. In summary, the drying process still dominates impacts compared to preservation methods that do not consume energy. Further research is needed to explore alternative drying methods, notably those that can be automated at scale, to identify energy-efficient methods and to explore the effects of different parameters (e.g. infrared drying or hot air drying) on biomass macromolecular and nutritional content.

The ensiling method in the study involved the use of a large concrete box built specifically for kelp ensilage. The process involves spreading kelp in the ensilage box (referred to as infrastructure in Fig. 7) using a small tractor, spreading of ensiling chemicals in the pile, and then covering the pile with a plastic sheet weighted down by sand and gravel to ensure that it is air-tight. These material inputs combined were found only to have a minor impact relative to other methods. The co-product of the ensilage, known as ensilage effluent, is also a liquid with relatively high biogas potential. Environmental impact mitigation credits were allocated in Thomas et al. (2021) to account for the production of biogas from this effluent. However, even though ensiling kelp performs well from an environmental point of view, the acidic and semidecayed state of ensiled kelp limits its use to relatively few applications, many of which are still the subjects of research and development.

The hang-drying method described in Thomas et al. (2021) was found to have the lowest impacts. However, it may be the least scalable, since it is the most labour intensive. The main impacts can be entirely attributed to production of the wooden frames from which the kelp hang (see Fig. 8). In practice, this method is entirely weather dependent. Drying methods have therefore evolved into a two-step process, starting with an initial outdoor drying process protected by an agricultural polytunnel. Once partially dried, the kelp can be brought indoors to be finished off under more controlled conditions in heated and well-ventilated indoor spaces.

All of the preservation methods involved additional processes, either relating to shredding the biomass prior to preservation, or to packing the biomass so that it can be stored safely after preservation processes are complete. These can also be seen in Fig. 6 as the grey parts of the bars. Though these additional processes or items are nearly insignificant for most preservation methods and impact categories, plastic storage bags for freezing were found to have a relatively large impact contribution, especially in terms of abiotic depletion. This is due to the frozen biomass being relatively voluminous and thus requiring far more bags to store one ton of fresh biomass, than drying methods which involve packing a lower volume of dried biomass. 


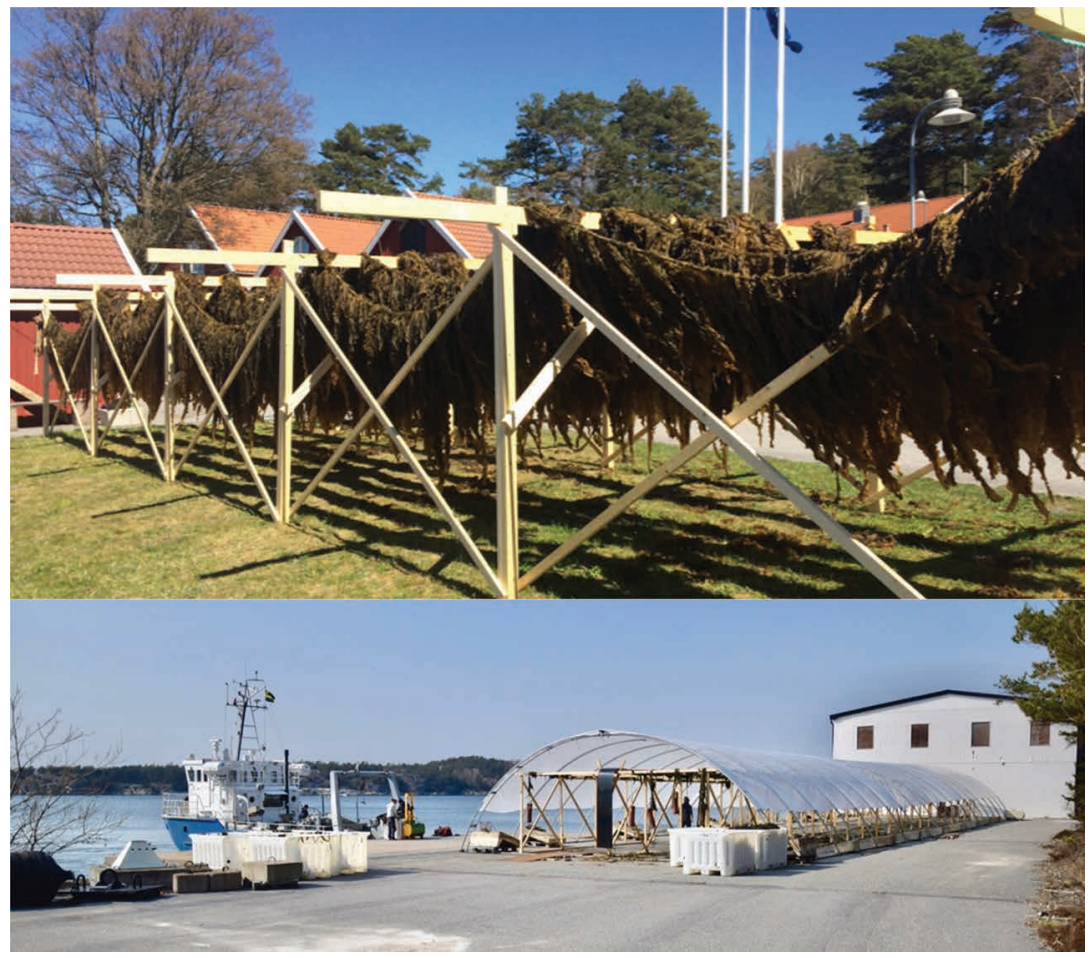

Figure 8 Above: Early trials of outdoor hang-drying in spring 2017 at the Sven Lovén Centre, Tjarnö (photo: Gunnar Cervin \& Göran Nylund). Below: Polytunnel-protected outdoor drying in Spring 2019 at the Koster Alg facility on the Swedish west coast (photo: Jean-Baptiste Thomas).

\section{Conclusion}

The environmental performance of seaweed cultivation and processing systems is a complex puzzle. It consists of both direct local effects and effects resulting from the production and the end-of-life of material and energy inputs to the system. These latter types of impacts can be gauged by means of environmental LCA. This chapter presents an overview of the environmental performance of a kelp hatchery, cultivation and preservation system, based primarily on an LCA by Thomas et al. (2021). The knowledge gained by conducting an LCA on these types of production systems enables informed environmental optimisation of supply chain activities.

The main impact hotspots identified in both Thomas et al. (2021) and other LCA studies are a result of the physical cultivation infrastructure at sea, notably the robust and marine-grade ropes that are utilised in longline systems. Some studies also report large impact contributions from the processing of harvested 
biomass. Thomas et al. (2021), for example, found that freezing and air cabinet drying, both high-energy preservation methods, are important impact hotspots in the process chain. Infrastructure at sea and high-energy preservation methods are thus life cycle stages where environmental optimisation can have important impact-reduction effects.

Some studies in the LCA literature have also found that the transport of materials at sea can also contribute significantly to environmental impacts. This is notably the case in production systems that require transportation over longer distances. This is not the case in Thomas et al. (2021), where the short distance from port to farm resulted in a low-impact contribution from sea transport.

Other sub-processes, such as those of the juvenile hatchery or the alternative preservation methods of hang-drying and ensiling, were found to have lower environmental impact contributions. However, environmental optimisation strategies should still be pursued, typically based on implementing energyefficient technologies, or of strategies that can mitigate critical risks such as hatchery failure.

Some LCA studies (notably Seghetta et al. 2016, 2017; and Thomas et al. 2021 ) attempt to account for the uptake of nutrients and carbon assimilated by harvested biomass from marine environments. These nutrient and carbon flows from marine environments to seaweed products (and thus back to society) attract environmental impact mitigation credits, thus (partially) offsetting impacts resulting from emissions. The result is that these product systems are found to perform very well in terms of mitigating eutrophication and from a carbon perspective.

\section{Limitations of LCA}

Opportunities abound for methodological development of the LCA in the coming decades. Many environmental aspects of product systems are not well covered by the LCA, notably the effects on the immediate local environment. In seaweed product systems, this could include the effects on local biodiversity, resulting from the presence of marine infrastructure. Ecosystem services are also typically not covered in the LCA. To study local impacts, alternative forms of assessment are needed. Research is ongoing to incorporate these perspectives into LCA methodology.

The spatial context of environmental impacts is also an area of LCA methodological development in need of further development. Eutrophication or oligotrophic conditions, for instance, are highly localised environmental states, each being particularly sensitive or resistant to different actions. The addition of nutrients to an oligotrophic or eutrophic lake will have very different consequences, with the former likely to shift to a eutrophic state, whereas the addition of nutrients to an already eutrophic lake will likely not cause a major 
regime shift. In LCA, these sorts of contexts of pre-existing environmental states and the sensitivity of these states is usually considered.

Another concern regarding LCA relates to its wider use in decision making and in reports: life cycle perspectives are often overlooked as these can be tricky to grasp by non-experts. A recent example of this is the latest Seaweed for Europe report 'Hidden champion of the ocean: seaweed as a growth engine for a sustainable European future', which omits recognition of the wide range of LCA studies on the topic. This could be considered to be symptomatic of the complexities of the LCA methods and interpretation, or perhaps of the lack of effective LCA communication strategies for research output. Regardless of the reasons, this embodies a significant challenge for future LCA developments. Efforts need to be directed to bridge the gap between LCA research and the communication of clear and useful outputs, for instance, by using the Sustainable Development Goals.

\section{Future trends in seaweed-related LCA}

Over the past ten years, seaweed-related LCA studies have attempted to shed light on the environmental performance of seaweed production systems, particularly within a context of seaweed being utilised as a substrate for bioenergy production. Most of these studies have been explorative in nature, based on proof-of-concept pilots to shed light on cultivation systems, and on hypothetical or experimental data for later life cycle stages (e.g. bioenergy conversion). Several studies have sought to extrapolate scales of production systems based on pilot data, to shed light on the plausible impacts and contributions to sustainability of the sector in the coming decades.

Given the limited availability of data from this emerging field, much of the focus of these LCAs has been on the earlier life cycle stages, notably the cultivation stage, in support of optimising the pilot cultivation infrastructure systems. In addition to these, data emanating from seaweed biorefinery research projects (e.g. the Danish MAB3 project) have also supported LCAs with the aim of assessing alternative pathways through biorefinery concepts. These scenario-based LCAs are also typically based on laboratory-scale experiments resulting in different combinations of end-and by-products, thus giving a sense of the potential of biorefinery activities.

Looking forward into the coming decade, European seaweed production is at a tipping point, transforming from a series of pilot projects into an emergent sector. Thomas et al. (2021) represents one of the first LCA case studies that shifts $\mathrm{LCl}$ focus from hypothetical and scaled production systems to a specific case-oriented pilot/commercial production system, though the scope remains on established early life cycle stages. A myriad of alternative pathways remain for the later life cycle stages, namely biorefinery processing, 
use-phases and end-of-life of a wide range of seaweed products. Furthermore, as seaweed farming practices scale up and move offshore, follow-up studies to Thomas et al. (2021) will be needed to document the potential of economies of scale.

As new technologies evolve, scales increase and pathway concepts materialise into commercial enterprises for specific products and processing methods, data will become available for robust LCAs to be undertaken. This will enable reliable comparisons to be made between non-renewable or fossil-based products that can be replaced by seaweed-based products (e.g. comparisons of synthetic plastics vs. alginate biopolymers). In summary, as the European seaweed industry emerges in the coming years, more LCAs will be needed to optimise the performance and guide the design principles of cultivation systems, preservation and processing methods, to ensure that the European seaweed industry delivers on its promise as a low-carbon, environmentally beneficial biomass.

\section{Where to look for further information}

\subsection{Seaweed-related LCA articles listed in chronological order of publication}

- Langlois, Juliette, Jean-François Sassi, Gwenaelle Jard, Jean-Philippe Steyer, Jean-Philippe Delgenes, and Arnaud Hélias. (2012). 'Life cycle assessment of biomethane from offshore-cultivated seaweed', Biofuels, Bioproducts and Biorefining, 6: 387-404.

- Alvarado-Morales, Merlin, Alessio Boldrin, Dimitar B. Karakashev, Susan L. Holdt, Irini Angelidaki, and Thomas Astrup. (2013). 'Life cycle assessment of biofuel production from brown seaweed in Nordic conditions', Bioresource Technology, 129: 92-99.

- Aitken, Douglas, Cristian Bulboa, Alex Godoy-Faundez, Juan L. TurrionGomez, and Blanca Antizar-Ladislao. (2014). 'Life cycle assessment of macroalgae cultivation and processing for biofuel production', Journal of Cleaner Production, 75: 45-56.

- Brockmann, Doris, Charlotte Pradinaud, Jennifer Champenois, Maud Benoit, and Arnaud Hélias. (2015). 'Environmental assessment of bioethanol from onshore grown green seaweed', Biofuels, Bioproducts and Biorefining, 9: 696-708.

- Cappelli, Andrea, Emanuele Gigli, Francesco Romagnoli, Silvano Simoni, Dagnija Blumberga, Massimiliano Palerno, and Elisa Guerriero. (2015). 'Co-digestion of macroalgae for biogas production: an LCA-based environmental evaluation', Energy Procedia, 72: 3-10.

- Taelman, Sue Ellen, Jennifer Champenois, Maeve D. Edwards, Steven De Meester, and Jo Dewulf. (2015). 'Comparative environmental life cycle 
assessment of two seaweed cultivation systems in North West Europe with a focus on quantifying sea surface occupation', Algal Research, 11: 173-183.

- Seghetta, Michele, Xiaoru Hou, Simone Bastianoni, Anne-Belinda Bjerre, and Marianne Thomsen. (2016). 'Life cycle assessment of macroalgal biorefinery for the production of ethanol, proteins and fertilizers - a step towards a regenerative bioeconomy', Journal of Cleaner Production, 137: 1158-1169.

- Jung, Kyung A., Seong-Rin Lim, Yoori Kim, and Jong Moon Park. (2017). 'Opportunity and challenge of seaweed bioethanol based on life cycle $\mathrm{CO}_{2}$ assessment', Environmental Progress \& Sustainable Energy, 36: 200-207.

- Seghetta, M., D. Romeo, M. D’Este, M. Alvarado-Morales, I. Angelidaki, S. Bastianoni, and M. Thomsen. (2017). 'Seaweed as innovative feedstock for energy and feed - evaluating the impacts through a Life Cycle Assessment', Journal of Cleaner Production, 150: 1-15.

- Van Oirschot, Roel, Jean-Baptiste E. Thomas, Fredrik Gröndahl, Karen P. J. Fortuin, Willem Brandenburg, and José Potting. (2017). 'Explorative environmental life cycle assessment for system design of seaweed cultivation and drying', Algal Research, 27: 43-54.

- Helmes, Roel J. K., Ana M. López-Contreras, Maud Benoit, Helena Abreu, Julie Maguire, Fiona Moejes, and Sander W. K. van den Burg. (2018). 'Environmental impacts of experimental production of lactic acid for bioplastics from Ulva spp.', Sustainability, 10: 2462.

- Nishikawa, Emily, Meuris Gurgel Carlos da Silva, and Melissa Gurgel Adeodato Vieira. (2018). 'Cadmium biosorption by alginate extraction waste and process overview in Life Cycle Assessment context', Journal of Cleaner Production, 178: 166-175.

- Vijay Anand, K. G., K. Eswaran, and Arup Ghosh. (2018). 'Life cycle impact assessment of a seaweed product obtained from Gracilaria edulis - a potent plant biostimulant', Journal of Cleaner Production, 170: 1621-1627.

- Parsons, Sophie, Michael J. Allen, Felix Abeln, Marcelle McManus, and Christopher J. Chuck. (2019). 'Sustainability and life cycle assessment (LCA) of macroalgae-derived single cell oils', Journal of Cleaner Production, 232: 1272-1281.

- Heery, Eliza C., Kay Yee Lian, Lynette H. L. Loke, Hugh T. W. Tan, and Peter A. Todd. (2020). 'Evaluating seaweed farming as an eco-engineering strategy for 'blue' shoreline infrastructure', Ecological Engineering, 152: 105857.

- Ögmundarson, Ólafur, Sumesh Sukumara, Alexis Laurent, and Peter Fantke. (2020). 'Environmental hotspots of lactic acid production systems', GCB Bioenergy, 12: 19-38.

- Thomas, J. B. E., M. Sodré Ribeiro, J. Potting, G. Cervin, G. M. Nylund, J. Olsson, E. Albers, I. Undeland, H. Pavia, and F. Gröndahl. (2021). 'A comparative environmental life cycle assessment of hatchery, cultivation, and preservation of the kelp Saccharina latissima', ICES Journal of Marine Science. 


\section{References}

Alvarez-Hess, P. S., Little, S. M., Moate, P. J., Jacobs, J. L., Beauchemin, K. A.. and Eckard, R. J. (2019). A partial life cycle assessment of the greenhouse gas mitigation potential of feeding 3-nitrooxypropanol and nitrate to cattle, Agricultural Systems 169(February), 14-23.

Baumann, H. and Tillman, A. (2004). The Hitch Hiker's Guide to LCA. An Orientation in Life Cycle Assessment Methodology and Applications, Sweden, Lund: Studentlitteratur Ab.

Czyrnek-Delêtre, M. M., Rocca, S., Agostini, A., Giuntoli, J. and Murphy, J. D. (2017). Life cycle assessment of seaweed biomethane, generated from seaweed sourced from integrated multi-trophic aquaculture in temperate oceanic climates, Applied Energy 196, 34-50.

Duarte, C. M., Wu, J., Xiao, X., Bruhn, A. and Krause-Jensen, D. (2017). Can seaweed farming play a role in climate change mitigation and adaptation? Frontiers in Marine Science 4(100). https://doi.org/10.3389/fmars.2017.00100.

Guinée, J. B. (2002). Handbook on life cycle assessment operational guide to the ISO standards, The International Journal of Life Cycle Assessment 7(5), 311-313.

Handå, A., Forbord, S., Wang, X., Broch, O. J., Dahle, S. W., Størseth, T. R., Reitan, K. I., Olsen, Y. and Skjermo, J. (2013). Seasonal- and depth-dependent growth of cultivated kelp (Saccharina latissima) in close proximity to salmon (Salmo salar) aquaculture in Norway, Aquaculture 414-415, 191-201.

ILCD (2010). International Reference Life Cycle Data System (ILCD) Handbook-General Guide for Life Cycle Assessment-Detailed Guidance, Luxembourg: Publications Office of the European Union.

ISO 14044 (2006). ISO 14044:2006-Environmental Management-Life Cycle AssessmentRequirements and Guidelines. ISO/TC 207/SC 5, Switzerland, Geneva: International Standard Organisation.

Ketzer, F., Skarka, J. and Rösch, C. (2017). Critical review of microalgae LCA studies for bioenergy production, BioEnergy Research 11(1), 95-105.

Kouchaki-Penchah, H., Sharifi, M., Mousazadeh, H. and Zarea, H. (2015). Gate to gate life cycle assessment of flat pressed particleboard production in Islamic Republic of Iran, Journal of Cleaner Production 112(1), 343-350.

Lammens, T. M., Potting, J., Sanders, J. P. M. and De Boer, I. J. M. (2011). Environmental comparison of biobased chemicals from glutamic acid with their petrochemical equivalents, Environmental Science and Technology 45(19), 8521-8528.

Laurenti, A., Bakas, I., Clavreul, J., Bernstad, A., Niero, M., Gentil, E., Hauschild, M. Z. and Christensen, T. H. (2014). Review of LCA studies of solid waste management systemspart I: lessons learned and perspectives, Waste Management 34(3), 573-588.

McHugh, D. (2003). A Guide to the Seaweed Industry, Italy, Rome: Food and Agriculture Organization of the United Nations, Rome.

Meadows, D. (2015). Thinking in Systems. A Primer, London: Chelsea Green Publishing Co.

Porcelli, R., Dotto, F., Pezzolezi, L., Marazza, D., Greggio, N. and Righi, S. (2020). Comparative life cycle assessment of microalgae cultivation for non-energy purposes using different carbon dioxide sources, Science of the Total Environment 721(June), 137714.

Potting, J. and Blok, K. (1995). Life-cycle assessment of four types of floor covering, Journal of Cleaner Production 3(4), 201-213. 
Potting, J., Thomas, J.-B. E. and Gröndahl, F. (submitted). Stakeholder participation in sustainability assessment of non-wicked problems: the case of a future seaweed industry in Sweden, AMBIO-A Journal of the Human Environment.

Sills, D. L., Van Doren, L. G., Beal, C. and Raynor, E. (2020). The effect of functional unit and co-product handling methods on life cycle assessment of an algal biorefinery, Algal Research 46, 101770.

Taelman, S. E., Champenois, J., Edwards, M. D., De Meester, S. and Dewulf, J. (2015). Comparative environmental life cycle assessment of two seaweed cultivation systems in North West Europe with a focus on quantifying sea surface occupation, Algal Research 11, 173-183.

Thomas, J.-B. E. (2018). Insights on the sustainability of a Swedish seaweed industry. Doctoral thesis in Industrial Ecology, Stockholm, Sweden: KTH.

Thomas, J.-B. E., Sodré-Ribeiro,M., Potting, J., Cervin, G., Nylund, G. M., Visch, W., Olsson, J., Albers, E., Undeland, I., Pavia, H.. and Gröndahl, F. (2021). A comparative environmental life cycle assessment of hatchery, cultivation and preservation of the kelp Saccharina latissima, Journal of Marine Science 78(1), 451-467.

Thomas, J.-B. E., Sterner, M., Nylund, G. M., Albers, E., Edlund, U., Undeland, I., Welander, U., Gröndahl, F. and Pavia, H. (submitted). The effect of modifying cultivation depth, deployment and harvest times on the chemical composition of Saccharina latissima.

Van den Burg, S., Dagevos, H. and Helmes, R. (2018). Sustainable Seaweed Value-Chains Economics, Consumer Attitudes and Environmental Impacts, the Netherlands, Wageningen: Wageningen University \& Research.

Van Hal, J. W., Huijgen, W. J. J. and López-Contreras, A. M. (2014). Opportunities and challenges for seaweed in the biobased economy, Trends in Biotechnology 32(5), 231-233.

Van Oirschot, R., Thomas, J.-B. E., Gröndahl, F., Fortuin, K. P. J., Brandenburg, W. and Potting, J. (2017). Explorative environmental life cycle assessment for system design of seaweed cultivation and drying, Algal Research 27(November), 43-54.

Vilg, J. V., Nylund, G. M., Werner, T., Qvirist, L., Mayers, J. J., Pavia, H., Undeland, I. and Albers, E. (2015). Seasonal and spatial variation in biochemical composition of Saccharina latissima during a potential harvesting season for Western Sweden, Botanica Marina 58(6), 435-447. 